\title{
The Concentration of the Banking Industry and Its Exposure to Financial Contagion
}

\author{
Mario Eboli ${ }^{1}$ \\ ${ }^{1}$ Dipartimento di Economia Aziendale, Università 'G. d'Annunzio', Pescara, Italy \\ Correspondence: Mario Eboli, Dipartimento di Economia Aziendale, Università 'G. d'Annunzio', viale Pindaro \\ 42, 65127 Pescara, Italy. Tel: 0039-347-482-4246. E-mail: m.eboli@unich.it
}

Received: January 26, 2019

Accepted: February 27, 2019

Online Published: March 28, 2019

doi:10.5539/ijef.v11n4p95

URL: https://doi.org/10.5539/ijef.v11n4p95

\begin{abstract}
This paper focuses on the effects that the concentration of the banking industry has on its exposure to the risk of systemic crises due to direct, balance-sheet financial contagion. Studying three stylized (and analytically tractable) classes of interbank networks - namely the complete, star and ring networks - we show that the magnitude of the smallest insolvency shock that is capable of causing the default of all banks in the system depends on the degree of concentration of the industry. Concerning complete and ring interbank networks, we obtain that the more concentrated the banking system is, the smaller the magnitude of the shock that induces the insolvency of the entire system. That is, concentration renders the banking system more fragile. Conversely, we show that the opposite applies to star interbank networks - i.e. networks composed of a bank at the centre connected to a set of peripheral banks that are not connected among themselves. In this case, the more concentrated the industry, the larger the smallest shock that causes a systemic crisis, i.e. the smaller the exposure to systemic risk.
\end{abstract}

Keywords: bank industry concentration, systemic risk, financial contagion, interbank network stability

\section{Introduction and motivation}

Starting from the early '90s, banking, financial and insurance systems worldwide have undergone a remarkable process of consolidation and industry concentration. In the first decade of the century, this process led to an unprecedented level of concentration in the banking sector (Note 1). As a result, two-tiered national banking systems have emerged, each characterised by a limited number of very large banks and a large number of small banks (Note 2). Due to the magnitude and relevance of this phenomenon, numerous studies have tried to establish whether concentration enhances or worsens the stability and resilience of a banking system. This stream of literature provides conflicting results, both theoretical and empirical, that can be grouped into two opposite views of the issue. Some authors - e.g. Beck et al. (2006), Beck (2007), Berger et al. (2009), Evrensel (2008), Freixas and Rochet (2008) - present results that support the view that concentration improves that stability of banking systems, the so-called 'concentration-stability' hypothesis. Other authors - e.g. De Nicolò et al. (2004), Boyd et al. (2006), Uhde and Heimeshoff (2009), Shehzad et al. (2009) - put forward the opposite opinion, the 'concentration-fragility' hypothesis, which claims that concentration renders banking systems more prone to systemic crisis.

Most of the contributions mentioned above study the impact of industry concentration and consolidation on systemic stability by looking at the effects that the growth of the size and the market power of banks have on their stability. The variety of views and results appeared in the literature stems from the fact that these effects are ambiguous.

In this paper, we look at the relation between the concentration and stability of banking systems from a different viewpoint. We analyse the impact of industry concentration on the risk of systemic crises due to direct, balance-sheet financial contagion in interbank networks. As it is known, banks form networks of financial obligations. These networks arise from over-the-counter trading, payment systems, syndicated loans, etc. Moreover, interbank financial networks arise as risk-sharing devices: banks cross-hold liquid position in order to co-insure themselves against the liquidity risk due to customer deposits fluctuations. This network of obligations becomes a channel of transmission of financial distress if one or more banks in the system default. The direct transmission of losses, from the defaulting debtors to their creditors, has been widely studied in the literature on 
financial contagion. In what follows, we build upon the analytic results on the stability of complete, star and ring interbank networks put forward by Eboli (2018) and Castiglionesi and Eboli (2018). Varying the degree of concentration of these three types of interbank networks, we show that the concentration of the industry renders the complete and the ring networks more exposed to financial contagion and the risk of systemic crises, while the opposite applies to the star networks. To the best of our knowledge, the present paper is the first study of this type, i.e. the first application of interbank network theory to the analysis of the effects of the concentration of the banking industry on its stability.

The paper is organised as follows. Section 2 presents a review of the related literature. Section 3 introduces a formal model of an interbank network, and the stability results about complete, ring and star networks put forward by Eboli (2018) and Castiglionesi and Eboli (2018). Section 4 presents our results on the effects of concentration on these three types of networks. Conclusions are drawn in section 5.

\section{Related Literature}

Several scholars have investigated the relation that exists between the concentration of the banking industry and its stability, providing contrasting results on both theoretical and empirical grounds.

On the one hand, we have contributions that sustain the 'concentration-stability' hypothesis. Allen and Gale (2004) underline the fact that it is easier for the authorities to monitor the behaviour of a few large banks in highly concentrated banking systems. Other authors support the view that the bankruptcy risk of a bank decreases as its market power increases. Boyd et al. (2006) argue that concentration implies higher profits, hence more robust banks. Similarly, Evrensel (2008) and Berger and Bouwman (2013) argue that the high profits due to concentration increase the capital buffers of banks and renders them more capable of overcoming solvency and liquidity shocks. Freixas and Rochet (2008) also see a positive effect of market power on financial stability because of the higher profits that arise from market power, profits that improve the capability to absorb shocks. Beck et al. (2006) study the connection between market concentration and banking crises, using data on 69 countries for the period 1980-1997. They find that the more concentrated a banking system is, the smaller is the risk of crises. Along the same line, Beck et al. (2007) claim that large banks are more stable thanks to the higher diversification of their exposures.

On the other hand, the authors that support the 'concentration-fragility' hypothesis have a different view about the effects of consolidation and market power on stability. Uhde and Heimeshoff (2009) contend that larger banks can exploit economies of scale and achieve a more efficient diversification of their portfolios. Nonetheless, they find that concentration has a negative effect on the financial soundness of European banks, where the latter is measured in terms of Z-score. Boyd et al. (2006) argue that concertation and market power lead to higher interest rates on loans, inducing a higher risk of defaults because of the worsening of moral hazard and adverse selection problems in the credit market. Similarly, Forssbæck and Shehzad (2015) claim that market power in loan and deposit markets power has a stable and monotonically negative effect on banks' risks. Schaeck et al. (2009) also present empirical evidence in favour of the 'concentration-fragility' view, comparing the concentration of banking systems and the occurrence of crises in 38 countries over the period 1980-2003.

As discussed above, we investigate the concentration-stability issue from the viewpoint of the interbank network theory. Thus, our work is also related to the literature on financial networks and systemic risk. Starting from the seminal papers by Allen and Gale (2000) and Eisenberg and Noe (2001), many contributions have studied systemic risk in banking networks, both with analytical methods and with numerical simulations. Allen and Babus (2009) review this stream of literature. A more recent set of papers-Cabrales et al. (2017), Elliott et al. (2014), Glasserman and Young (2015) and Acemoglu et al. (2015) - focuses on the effects of the shape of an interbank network on its exposure to systemic risk. Cabrales et al. (2016) provide a thorough description of these contributions. The papers that are mostly related to the present one are Eboli (2018) and Castiglionesi and Eboli (2018) since we apply their results on the stability of complete, ring and star interbank networks. Eboli (2018) presents an analysis of direct contagion in financial networks based on flow network theory. The author compares the performance of these three types of networks in terms of thresholds of contagion, as explained below. Castiglionesi and Eboli (2018) analyse the efficiency of different interbank networks in moving liquidity from banks that experience a surplus of liquidity to banks that face a liquidity deficit. These authors evaluate the stability of complete and ring networks under some restrictions that ensure the complete transfer of liquidity from surplus banks to deficit banks in both networks. 


\section{Financial Contagion in Interbank Networks}

\subsection{An Interbank Network and Its Contagion Thresholds}

As customary, we model an interbank network as a directed and weighted graph, with nodes representing banks and links representing financial obligations between pairs of banks. Formally, let $N=(\Omega, \mathrm{L})$ be an interbank network composed of a set of $\mathrm{n}$ banks $\Omega=\left\{\omega_{i} \mid \mathrm{i}=1, \ldots, \mathrm{n}\right\}$ which are directly or indirectly connected to one another by a set of links $\mathrm{L}=\left\{d_{i j} \mid \mathrm{i} \neq \mathrm{j} ; \mathrm{i}, \mathrm{j}=1, \ldots, \mathrm{n}\right\}$, i.e. a set of financial obligations, where $d_{i j}$ is the amount that bank $\omega_{i}$ owes to bank $\omega_{j}$. Each of such banks is characterized by its own balance sheet $a_{i}+c_{i}=e_{i}+d_{i}+h_{i}$, where:

i) $\mathrm{a}_{\mathrm{i}} \in \mathrm{R}^{+}$is the value of the external assets owned by the $i$-th bank. Such assets are liabilities - shares, bonds and bank loans - of final users of funds, which are not in $\Omega$;

ii) $c_{i}=\sum_{j} d_{j i}$ is the sum of the internal assets - liabilities issued by other banks in $\Omega$ - held by bank $i$;

iii) $d_{i}=\sum_{j} d_{i j}$ is the internal debt of bank $i$, i.e., the sum of the liabilities issued by bank $i$ and held by other banks in $\Omega$;

iv) $h_{i}$ is the external debt of bank $\omega_{i}$, i.e., the amount of claims against bank $i$ held in the form of bonds and deposits by final claimants, such as households, who do not belong to $\Omega$;

v) $e_{i}$ is the value of the equity of the $i$-th bank, which is set residually by the budget identity $e_{i}=a_{i}+c_{i}-d_{i}-$ $h_{i}$.

Financial contagion in an interbank network $N$ occurs if one or more banks in $\Omega$ default on their obligations. As customary in the literature on financial contagion, we suppose that this happens because of an exogenous insolvency shock, a shock that consists of a loss of value of some of the external assets $a_{i}$ held by the banks. The propagation across $N$ of the losses caused by a shock is governed by the rules of limited liability, debt priority and pro-rata reimbursement of creditors. If a bank $\omega_{i}$ suffers a loss, this loss is first absorbed by its net worth, i.e. its equity $e_{i}$. If the bank defaults, i.e. if the loss is larger than $e_{i}$, then the residual loss is passed over to its creditors in $\Omega$, who receive a loss proportional to their exposure towards the defaulting bank.

Let $b_{i} \in[0,1]$ be a parameter that measures the fraction of the value of the asset $a_{i}$ which is lost upon the occurrence of the shock. If $b_{i}>0$, then the bank $\omega_{i}$ suffers a loss equal to $b_{i} a_{i}$. Formally, an exogenous shock is a vector of scalars $\left[b_{i} a_{i}\right], i=1, \ldots, n$, where at least one $b_{i}>0$, and its magnitude is $s=\sum_{i} b_{i} a_{i}$. Suppose that, upon the occurrence of a shock, one or more banks in $\Omega$ default. Let $\Omega^{-}=\left\{\omega_{i} \mid b_{i} a_{i}>e_{i}\right\}$ be the set of these primary defaults and let $\Omega^{+}=\left\{\omega_{i} \mid l_{i}>e_{i}\right\}$ be the set of secondary defaults, i.e. banks that default because of the losses $l_{i}$ received from their defaulting creditors in $\Omega$. To evaluate the resiliency of a network, we look at its first and final contagion thresholds:

Definition: The first contagion threshold of an interbank network $N$ is the value of the smallest shock that is capable of causing at least one secondary default. The final contagion threshold of an interbank network $N$ is the value of the smallest shock that is capable of causing the default of all banks in the network.

\subsection{The Contagion Thresholds of Complete, Ring and Star Networks}

In what follows, we focus on the response to shocks of three types of networks: the complete, the ring and the star network (Note 3). Complete networks are maximally connected; ring networks are minimally connected and maximally decentralised while star networks are minimally connected and maximally centralised. These three classes of networks are, respectively, the stylised example of dense networks, sparse and decentralised networks and sparse and centralised networks.

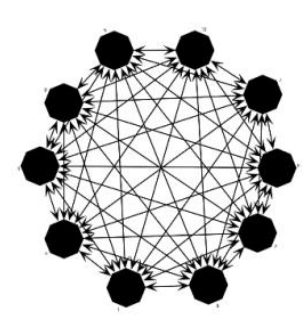

Complete Network

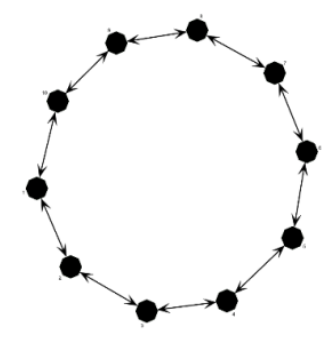

Ring Network

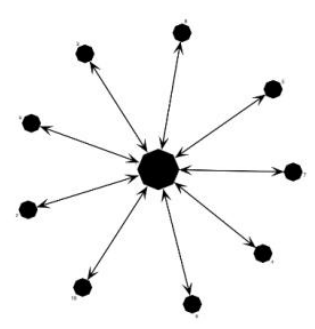

Star Network 


\subsubsection{Complete Networks}

An interbank network is called complete if its set of links is maximal, i.e. if each bank places a deposit in every other bank in the network. Formally, let $N^{c}=\left\{\Omega, L^{c}\right\}$, where $L^{c}=\left\{d_{i j} \mid i \neq j ; i, j=1, \ldots, n\right\}$, be a complete interbank network where all the links have the same weight (value) $d_{i j}$. In other words, in this class of networks, each bank evenly allocates its own interbank deposits $c_{i}$ in all other banks. In a complete network $N^{c}$, the first threshold and the final threshold of contagion coincide and are equal to

$$
\tau^{c}=n e_{i}+e_{i} \frac{h_{i}}{d_{i j}}=E+e_{i} \frac{h_{i}}{d_{i j}}
$$

where $E=\sum_{i} e_{i}=n e_{i}$ is the total amount of equity in the system. This result shows the robust-yet-fragile nature of a complete network. This network is fully resilient with respect to a shock of magnitude smaller than $\tau^{c}$ while it suffers a complete systemic meltdown if hit by shocks equal to or larger than the above threshold.

\subsubsection{Ring Networks}

A ring interbank network is a circular network where each bank has only two neighbours, its predecessor and its successor along the ring. That is, a ring network consists of a set of banks connected through a chain of obligations, a chain where the start node ad the final node coincide. Formally, a ring network $N^{r}=\left\{\Omega, L^{r}\right\}$ is such that $L^{c}=\left\{d_{i j} \mid i=1, \ldots, n-1, j=i+1\right\}$

Unlike the complete network, the ring network does not have a single final threshold of contagion but rather an entire range of such thresholds. The possible final thresholds of $N^{r}$ depend on the allocation of the external shock $s$ among the banks in the ring. We focus on the smallest and the largest possible final thresholds of this network.

1) The first contagion threshold of $N^{r}$ is

$$
\tau_{1}^{r}=e_{i}\left(2+\frac{h_{i}}{d_{i}}\right)
$$

2) The smallest possible final threshold of $\mathrm{N}^{\mathrm{r}}$ is equal to

$$
\tau_{2}^{r}=a_{i} \frac{n}{k}
$$

where $k$ is the largest integer such that

$$
k+2(k-1)\left[\left(1+\frac{h_{i}}{d_{i}}\right)^{k-1}-1\right] \leq \frac{a_{i}}{e_{i}}
$$

3) The largest possible final threshold of $\mathrm{N}^{\mathrm{r}}$ is equal to

$$
\ddot{\tau}_{2}^{r}=a_{i}(n-\ddot{k}+1),
$$

where $\ddot{k}$ is the largest integer such that

$$
\ddot{k}+2(\ddot{k}-1)\left[\left(1+\frac{h_{i}}{d_{i}}\right)^{\ddot{k}-1}-1\right] \leq \frac{a_{i}+d_{i}}{e_{i}}
$$

The integer $k$ is the number of secondary defaults caused by the bankruptcy of a single bank in a ring network, i.e. by an idiosyncratic shock $s=a_{i}$. The smallest possible final contagion threshold in $N^{r}$ corresponds to the most unfavourable scenario, that is when the primary defaults--the 'seeds' of contagion--are disposed along $N^{r}$ at regular intervals of length $k$. With this disposition, the scope of contagion of each primary defaults is maximal. In this most contagious scenario, $n / k$ primary defaults are sufficient to induce the default of all the other banks in the network, i.e. to reach the smallest of the possible final thresholds (Note 5).

Conversely, the disposition of primary defaults that minimises the impact of a shock is such that all primary defaults are adjacent to one another, forming an uninterrupted chain along the ring network. In this case, the shock causes a number of secondary defaults equal to $\ddot{k}-1$, and the shock must wipe out the assets of at least $(n-k+1)$ banks in order to achieve a complete systemic crisis.

\subsubsection{Star Networks}

A star interbank network is composed of a central node and a set of peripheral nodes. The central node, $\omega_{c}$, borrows from and lends to each of the n-1 peripheral nodes $\omega_{p}, p=1,2, \ldots, n-1$, which, in turn, have no financial obligations among themselves. Formally, a star network $N^{s}=\left\{\Omega, L^{s}\right\}$ is such that $L^{s}=\left\{d_{c p}, d_{p c} \mid p=\right.$ $1, \ldots, n-1\}$. Let $e_{c}$ and $e_{p}$ be the amount of equity, and $h_{c}$ and $h_{p}$ be the amount of customer deposits, held 
by the centre bank and a peripheral bank, respectively. As above, all links in $L^{S}$ have the same value $d_{p}$, that is, the deposits cross-held by the centre bank and each peripheral bank are all equal. The response to a shock of this network depends on the allocation of the initial losses between centre and periphery. We have three possible cases: 1$)$ the shock is idiosyncratic and borne by the central node alone: $\left.\Omega^{-}=\left\{\omega_{c}\right\} ; 2\right)$ the shock is borne by $\omega_{c}$ and by some peripheral nodes: $\Omega^{-}=\left\{\omega_{c}, \omega_{p} \mid\right.$ for some $p$ in $\left.\Omega \backslash \omega_{c}\right\}$, and 3) the shock is borne by peripheral nodes only: $\Omega^{-}=\left\{\omega_{p} \mid\right.$ for some $p$ in $\left.\Omega \backslash \omega_{c}\right\}$. In the first two cases, the first and final contagion thresholds coincide, like in a complete network:

1) If $\Omega^{-}=\left\{\omega_{c}\right\}$, then the first and the final contagion thresholds of $N^{s}$ are equal to

$$
\tau^{s}=(n-1) e_{p}+e_{c}+e_{p} \frac{h_{c}}{d_{p}}=E+e_{p} \frac{h_{c}}{d_{p}} .
$$

2) If $\Omega^{-}=\left\{\omega_{c}, \omega_{p} \mid\right.$ for some $p$ in $\left.\Omega \backslash \omega_{c}\right\}$ and for $s_{c}<\tau^{s}, 4$ then the first and the final contagion thresholds of $\mathrm{N}^{\mathrm{s}}$ are both equal to

$$
\ddot{\tau}^{s}=\left[E+e_{p} \frac{h_{c}}{d_{p}}\right]\left(1+\frac{h_{p}}{d_{p}}\right)-s_{c} \frac{h_{p}}{d_{p}}=\tau^{s}+\left(\tau^{s}-s_{c}\right) \frac{h_{p}}{d_{p}},
$$

where $s_{c}$ is the amount of exogenous initial losses suffered by the centre bank.

Conversely, the first and final contagion thresholds are not equal to one another if the exogenous shock hits peripheral banks only:

3) If $\Omega^{-}=\left\{\omega_{\mathrm{p}} \mid\right.$ for some $\mathrm{p}$ in $\left.\Omega \backslash \omega_{\mathrm{c}}\right\}$, then the first and final thresholds of contagion are, respectively, equal to

$$
\tau_{1}^{S}=m e_{p}+e_{c} \frac{h_{p}}{d_{p}}
$$

and

$$
\tau_{2}^{S}=\left[E+e_{p} \frac{h_{c}}{d_{p}}\right]\left(1+\frac{h_{p}}{d_{p}}\right)=\tau^{S}\left(1+\frac{h_{p}}{d_{p}}\right) .
$$

These results show that the star network, on the one hand, is exposed to default contagion for relatively small shocks that hit peripheral banks only, i.e. for shocks $s \geq \tau_{1}^{s}$ that are sufficient to induce the default of the centre bank. On the other hand, $N^{s}$ has a robust-yet-fragile response to large shocks: once the centre bank is in default, the losses are evenly spread among all the other banks in the network and, as a consequence, they all default together if the shock is sufficiently large, i.e. if $s \geq \tau_{2}^{s}$.

\section{The Effects of Concentration on the Contagion Thresholds of Complete, Star and Ring Interbank Networks}

It can be checked by inspection that all final thresholds of contagion characterised above $-\tau^{c}, \tau^{s}, \ddot{\tau}^{s}, \tau_{2}^{s}, \tau_{2}^{r}, \ddot{\tau}_{2}^{r}-$ grow as the number of banks in a network, $n=|\Omega|$, grows. The growth of the population, $n$, of the networks at hand renders them more robust because of two distinct effects:

i) the growth of the size of the financial system represented by $N$, and of its total stock of equity, $E$;

ii) the decrease of the degree of industry concentration of the financial system.

The rationale of point (i) is almost self-evident, recalling that the equity endowment of a bank determines its capacity to absorb a shock, and this equally applies to a set of banks hence to all networks. Thus, it is not surprising that a larger network requires a larger shock to cause a systemic crisis.

Conversely, the effects of industry concentration on the exposure to default contagion of the networks at hand are less obvious. Indeed, we have that these effects are not the same for all networks. To see this, let us isolate the effects of concentration, point (ii), from the effects of the growth of the financial system, point (i). We do so by keeping constant the size of the banking system in terms of the stocks intermediated by the industry - i.e., the total external assets, $A$, the total equity, $E$, the total external liabilities, $H$, and the total interbank debt, $D$ - while varying the number of banks $n$. This constraint implies that, as $n$ grows, the size of each bank in the system decreases. As the population of the network grows while its stocks $A, E, H$, and $D$ remain constant, the value of each balance-sheet item $e_{i}=E / n, a_{i}=A / n, d_{i}=D / n$ and $h_{i}=H / n$ decrease proportionally. With this restriction, the concentration of the industry, measured with the Hirschman-Herfindahl index or the Concentration Ratio Cr, diminishes as $n$ grows. Moreover, we assume that each network at hand is composed of banks of equal size. Under these assumptions, we have the following results: 
Proposition 1: The threshold $\tau^{c}$ of a complete interbank network $N^{c}$ increases in $n$.

Proof: The first addendum of (1), $E$, is constant by assumption. The second addendum of (1) can be written as $e_{i} \cdot h_{i} / d_{i j}=(n-1) e_{i} \cdot h_{i} / d_{i}=E h_{i} / d_{i}-e_{i} \cdot h_{i} / d_{i}$. Since $h_{i}=H / n, d_{i}=D / n$ and $e_{i}=E / n$, the first addendum of the latter equation is constant while the second addendum decreases in $n$. Therefore, $\tau^{c}$ increases in $n$.

As $n$ grows and the concentration of the industry diminishes, a complete network $N^{c}$ becomes more robust, in the sense that range of the exogenous shock $s$ for which the network is entirely resilient, $s<\tau^{c}$, grows as $n$ grows. Under the above-stated assumptions, the more concentrated the industry is, the smaller is the shock capable of generating a systemic crisis, i.e. the more the system is exposed to systemic risk. The above result shows that the stability of a complete network deteriorates because of industry concentration, a result in line with the 'concentration-fragility' hypothesis.

We obtain a similar result for the class of ring networks:

Proposition 2: In a ring network $N^{r}$, we have that as $n$ grows:

1). The first contagion threshold, $\tau_{1}^{r}$, decreases.

2). The smallest possible final contagion threshold, $\tau_{2}^{r}$, i) remains constant while ii) the probability of its occurrence decreases.

3). The largest possible final contagion threshold, $\ddot{\tau}_{2}^{r}$, increases.

\section{Proof:}

1. $\tau_{1}^{r}=e_{i}\left(2+h_{i} / d_{i}\right)$ decreases in $n$ because $e_{i}=E / n$ diminishes as $n$ grows while $h_{i} / d_{i}$ remains constant.

2. i) recall that $a_{i}=A / n$ and rewrite (7) as $\tau_{2}^{r}=A / k$, which is invariant with respect to $n$. ii) First note that the above-defined parameters $k$ and $\ddot{k}$ remain constant as $n$ changes because the ratios $h_{i} / d_{i}, a_{i} / e_{i}$ and $\left(a_{i}+\right.$ $\left.d_{i}\right) / e_{i}$ remain constant as $n$ changes. Suppose now that a shock $s=a_{i} \cdot n / k$ occurs in a ring network $N^{r}$ composed of $n$ banks, and let $m=n / k$. In other words, let us assume that the shock causes $m$ primary defaults out of $n$ banks in the ring. There are

$$
\left(\begin{array}{l}
n \\
m
\end{array}\right)=\frac{n !}{m !(n-m) !}
$$

combinations of $m$ primary defaults out of $n$ banks, all equally likely to occur, each with probability $m !(n-m) ! / n !$. There are $k$ of these combinations such that the $m$ primary defaults are disposed at a regular distance $k$ from one another. The probability that one of these $k$ combinations occurs, provided that there are $m$ primary defaults, is $\mathrm{k}$. $\mathrm{m} !(\mathrm{n}-\mathrm{m}) ! / \mathrm{n} !$, that is strictly decreasing in $\mathrm{n}$.

3. To see that $\ddot{\tau}_{2}^{r}$ increases in $n$, rewrite $(8)$ as $\ddot{\tau}_{2}^{r}=(n-\ddot{k}+1) A / n=A-(\ddot{k}-1) A / n$ and recall that $A$ is constant by assumption. q.e.d.

As $n$ grows and the banks in the system become progressively more numerous and of smaller size, a ring network $N^{r}$ becomes less resilient with respect to small shocks, as shown by the fact that the first contagion threshold decreases in $n$. On the other hand, as $n$ grows, a ring network becomes more stable with respect to large shocks, i.e. it becomes less exposed to systemic risk. The magnitude of the shock that corresponds to the worst case scenario, i.e. the smallest possible final threshold $\tau_{2}^{r}$, does not change but the probability of its occurrence decreases as $n$ grows. This result implies that as the concentration of the industry grows (and $n$ diminishes), the likelihood of a systemic crisis in $N^{r}$ increases. This effect of concentration is even more evident looking at the largest possible final contagion threshold of the ring network, $\ddot{\tau}_{2}^{r}$ : the smaller $n$, the smaller $\ddot{\tau}_{2}^{r}$ and the more the network is exposed to systemic risk. Again, a result in line with the 'concentration-fragility' hypothesis. In sum, the more concentrated a ring interbank network is, the less it is exposed to local episodes of contagion, due to relatively small shocks, and the more it is exposed to the risk of a whole systemic crisis.

We now proceed to show that the opposite result applies to the class of star networks.

Proposition 3: The contagion thresholds of a star network $N^{s}, \tau_{1}^{s}, \tau^{s}, \tau_{2}^{s}$ and $\ddot{\tau}^{s}$, decrease as $n$ grows.

Proof: 1). The first addendum of (4), $m e_{p}$, decreases in $n$ because i) $m$ does not change with $n . m$, the smallest number of primary peripheral defaults sufficient to cause the default of the centre node, is s.t. $m l_{p} \geq e_{c}$, where $l_{p}=\left(a_{p}-e_{p}\right) /\left(h_{p}+d_{p}\right)$ is the loss that a single peripheral bank in default, subject to an idiosyncratic shock $s_{p}=a_{p}$, sends to the centre bank. Since all the balance sheet items $a_{p}, e_{p}, h_{p}, d_{p}$ and $e_{c}$ vary in the same exact proportion as $n$ changes, so do $l_{p}$ and $e_{c}$. Consequently, $m$ remains constant while $n$ changes and $e_{p}=E / n$ 
diminishes as $n$ grows. ii) The second addendum of (4), $e_{c} h_{p} / d_{p}$, decreases in $n$ because $h_{p} / d_{p}$ does not change with $n$ while $e_{c}=E / n$ diminishes as $n$ grows.

2). The first addendum of (2), $E$, is constant by assumption. The second addendum of (2), $e_{p} \cdot h_{c} / d_{p}$, diminishes in $n$ because $h_{c} / d_{p}$ remains constant while $n$ changes and $e_{p}=E / n$ diminishes as $n$ grows.

3). Since $\tau^{s}$ diminishes in $n$ and $h_{p} / d_{p}$ does not change with $n$, then $\tau_{2}^{s}=\tau^{s}\left(1+h_{p} / d_{p}\right)$ also decreases as $n$ grows.

4). Since $\tau^{s}$ diminishes in $n$ and the exogenously given shock to the centre bank, $s_{c}$, does not change with $n$, then $\ddot{\tau}^{s}=\tau^{s}+\left(\tau^{s}-s_{c}\right) h_{p} / d_{p}$ also decreases as $n$ grows.

Contrary to what happens with complete and ring networks, all contagion thresholds of a star network $N^{s}$ decrease as $n$ grows. This result means that, as $n$ grows, the magnitude of the shocks that can cause a systemic crisis in $N^{s}$ become progressively smaller and, consequently, the industry becomes progressively more exposed to systemic risk. In other words, higher concentration (lower $n$ ) renders a star interbank network more resilient to direct financial contagion, a result in line with the 'concentration-stability' hypothesis.

\section{Conclusions}

A stream of economic and financial literature addresses the relationship between the degree of concentration of a banking system and its stability. This literature provides contrasting results, with two opposite views: the so-called 'concentration-stability' and 'concentration-fragility' hypotheses. The ambition of this paper is to contribute to this line of research. We do so by presenting analytic results on the effects that the concentration of the banking industry has on the risk of the occurrence of a specific type of systemic crisis. We focus on the systemic risk due to exogenous insolvency shocks that propagate across the industry along the web of obligations that form an interbank network. Building on results concerning the stability of complete, ring and star interbank networks, put forward by Castiglionesi and Eboli (2018) and Eboli (2018), we investigate the impact of the banking industry concentration on the so-called 'contagion thresholds' of these three classes of interbank networks. A contagion threshold is the magnitude of the smallest shock that can cause contagion and systemic crises in an interbank network.

Our results show that the contagion thresholds of complete and ring interbank networks decrease as the degree of concentration of the system increases: concentration makes these networks more exposed to the risk of systemic crisis. Conversely, we obtain that the final contagion thresholds of star interbank networks display the opposite behaviour: they grow as the degree of concentration grows. In this case, concentration enhances stability making the industry less exposed to the risk of systemic crisis.

Our results shed some light on the impact of industry concentration on the stability of interbank networks, where the latter is evaluated with respect to the risk of episodes of direct financial contagion leading to systemic insolvency crises. To the best of our knowledge, this is the first paper to address this specific issue. The theorems presented in this paper indicate that the concentration/stability controversy mentioned above must take into account the structure of the interbank networks. As argued above, concentration renders less stable the banking systems that form highly decentralised interbank networks, either dense or sparse. Conversely, banking industries that form highly centralised interbank networks become more stable with concentration. The analysis presented here, however, is limited to the case where all banks in a network have the same size. The process of concentration of the banking industry has also been a process of consolidation. The recent empirical evidence shows banking systems composed of a few very large banks and a multitude of small and medium-sized banks. A natural and interesting development of the present work is the extension of the analysis to the case of interbank networks composed of banks of different sizes. This extension would embrace the study of the two-tiered core-periphery banking systems, described by Craig and van Peters (2004), and star networks with very large banks at the centre (also known as 'money centres'), studied by Castiglionesi and Eboli (218). This line of research is on our agenda.

\section{References}

Acemoglu, D., Ozdaglar, A., \& Tahbaz-Salehi, A. (2015). Systemic risk and stability in financial networks. American Economic Review, 105(2), 564-608. https://doi.org/10.1257/aer.20130456

Allen, F., \& Gale, D. (2000). Financial Contagion. Journal of Political Economy, 108, 1-33. https://doi.org/10.1086/262109 
Allen, F., \& Babus, A. (2009). Networks in finance. In P. Kleindorfer, J. Wind, \& R. E. Gunther (Eds.), The Network Challenge. Wharton School Publishing.

Beck, T. (2007). Bank Concentration and Fragility. Impact and Mechanics. In M. Carey, \& R. M. Stulz (Eds.), The Risks of Financial Institutions. University of Chicago Press. https://doi.org/10.7208/chicago/9780226092980.003.0006

Beck, T., Demirgüç-Kunta, A., \& Levine, R. (2006). Bank concentration, competition, and crises: First results. Journal of Banking \& Finance, 30(5), 1581-1603. https://doi.org/10.1016/j.jbankfin.2005.05.010

Berger, A. N., \& Bouwman, C. (2013). How does capital affect bank performance during financial crises? Journal of Financial Economics, 109(1), 146-176. https://doi.org/10.1016/j.jfineco.2013.02.008

Berger, A. N., Klapper, L. F., \& Turk-Ariss, R. (2009). Bank Competition and Financial Stability. Journal of Financial Services Research, 35(2), 99-118. https://doi.org/10.1007/s10693-008-0050-7

Boyd, H., De Nicolò, G., \& Jala, A. M. (2006). Bank Risk-Taking and Competition Revisited: New Theory and New Evidence. IMF Working Paper No. 06/297. https://doi.org/10.5089/9781451865578.001

Cabrales, A., Gottardi, P., \& Vega-Redondo, F. (2016). Financial Contagion in Networks. In the Oxford Handbook of the Economics of Networks, OUP, chapter 20.

Cabrales, A., Gottardi, P., \& Vega-Redondo, F. (2017). Risk Sharing and Contagion in Networks. Review of Financial Studies, 30(9), 3086-3127. https://doi.org/10.1093/rfs/hhx077

Castiglionesi, F., \& Eboli, M. (2018). Liquidity flows in interbank networks. Review of Finance, 22(4), 1291-1334. https://doi.org/10.1093/rof/rfy013

Craig, B., \& von Peter, G. (2014). Interbank Tiering and Money Center Banks. Journal of Financial Intermediation, 23(3), 322-347. https://doi.org/10.1016/j.jfi.2014.02.003

De Nicolò, G., Bartholomew, P., Jahanara, P. M., \& Zaman, M. Z. (2004). Bank Consolidation, Internationalization, and Conglomeration: Trends and Implications for Financial Risk. Financial Markets, Institutions \& Instruments, 13(5). https://doi.org/10.1111/j.0963-8008.2004.00076.x

Deltuvaite, V. (2010). The concentration-stability relationship in the banking system: An empirical research. Economics and Management, (15).

Eboli, M. (2018). A Flow Network Analysis of Direct Balance-sheet Contagion in Financial Networks. submitted, Retrieved from https://www.researchgate.net/publication/328630770_Revised_version_A_flow_network_analysis_of_direc t_balance-sheet_contagion_in_financial_networks

Eisenberg, L., \& Noe, T. H. (2001). Systemic risk in financial systems. Management Science, 47(2), 236-249. https://doi.org/10.1287/mnsc.47.2.236.9835

Elliott, M., Golub, B., \& Jackson, M. (2014). Financial networks and contagion. American Economic Review, 104(10), 3115-3153. https://doi.org/10.1257/aer.104.10.3115

Evrensel, A. (2008). Banking crisis and financial structure: A survival-time analysis. International Review of Economics and Finance, 17(4), 589-602. https://doi.org/10.1016/j.iref.2007.07.002

Forssbæck, J., \& Shehzad, C. T. (2015). The Conditional Effects of Market Power on Bank Risk--Cross-Country Evidence. Review of Finance, 19(5). https://doi.org/10.1093/rof/rfu044

Freixas, X., \& Rochet, J. C. H. (2008). Microeconomics of Banking (2nd ed.). MIT Press.

Glasserman, P., \& Young, H. P. (2015). How likely is contagion in financial networks? Journal of Banking and Finance, (50), 383-399. https://doi.org/10.1016/j.jbankfin.2014.02.006

Shaeck, K., Chiak, S., \& Wolfe, S. (2009). Are Competitive Banking Systems More Stable? Journal of Money, Credit and Banking. https://doi.org/10.1111/j.1538-4616.2009.00228.x

Uhde, A., \& Heimeshoff, U. (2009). Consolidation in banking and financial stability in Europe: Empirical evidence. Journal of Banking \& Finance, 33(7), 1299-1311. https://doi.org/10.1016/j.jbankfin.2009.01.006

\section{Notes}

Note 1. According to Deltuvaite (2010) and to the literature cited therein, in those years the average value of the CR3 ratio in the national banking industries became larger than 80 per cent, in 72 countries, and larger than 72 
per cent in 160 countries.

Note 2. See, inter alia, Craig, B. and von Peter, G. (2014).

Note 3. Castiglionesi and Eboli (2018) established the contagion thresholds in eqs. (1) - (5) below, concerning complete and star networks (see propositions 4, 5 and 6 therein), while Eboli (2018), in theorem 5, demonstrates the contagion thresholds in $(6)-(8)$.

Note 4. For shocks s.t. $s_{c}>\tau^{s}$, the threshold in (2) applies.

Note 5. The variable $k$ takes on rather small values, for plausible values of leverage and interbank exposures. Eboli (2018) shows that, even in the most contagious scenarios, with large interbank exposures and a low equity/asset ratios, $k$ is at the most equal to 3 . The same applies to the variable $\ddot{k}$ below.

\section{Copyrights}

Copyright for this article is retained by the author(s), with first publication rights granted to the journal.

This is an open-access article distributed under the terms and conditions of the Creative Commons Attribution license (http://creativecommons.org/licenses/by/4.0/). 